\title{
SOLO EN LA OSCURIDAD DE RAMÓN DÍAZ ETEROVIC: LITERATURA SOBRE EL NARCOTRÁFICO ANTES DE LA NARCOLITERATURA*
}

\author{
SOLO EN LA OSCURIDAD BY RAMÓN DÍAZ ETEROVIC: \\ LITERATURE ON DRUG TRAFFICKING BEFORE NARCO-LITERATURE
}

\author{
AINHOA VÁSQUEZ MEJÍAS ${ }^{* *}$
}

Resumen: En el año 1992, antes de la divulgación de la novela del escritor colombiano Fernando Vallejo, La virgen de los sicarios, de 1994, que daría origen al boom de la denominada narcoliteratura, el escritor chileno Ramón Díaz Eterovic, publicaba Solo en la oscuridad, una obra que, a la luz de las investigaciones sobre narconarrativa y, considerando las características narratológicas de este género, hoy podríamos leer desde este modelo. Previo a la abundancia de textos narcoliterarios, Díaz Eterovic ya aventuraba algunos de sus rasgos: estética traqueta, personajes femeninos víctimas y la visibilización de redes transnacionales en este lucrativo negocio. No obstante, son sus diferencias las que validan la novela en su dimensión ética: los narcotraficantes no son romantizados, sino representados como criminales despiadados $y$, a pesar de que el detective es un desencantado del sistema político, prima la seguridad de que aún queda gente honesta. Estos elementos, por lo tanto, la posicionan como un antecedente de la narconarrativa, a la vez que la diferencian de esta por su postura crítica ante el fenómeno del narcotráfico.

Palabras Clave: Narcoliteratura, literatura policial, Ramón Díaz Eterovic.

AвstRact: Before the boom of so-called narcoliterature initiated by the release of the Colombian novel La virgen de los sicarios (Fernando Vallejo, 1994), the Chilean writer, Ramón Díaz Eterovic, published Solo en la oscuridad (1992), a novel that may be read as a precursor to this literary phenomenon, given the narratological characteristics highlighted by recent research into the genre. Prior to the abundance of narcoliterary texts, Díaz Eterovic already exhibited some of their traits: aesthetic traqueta, feminine victims and the description of the transnational networks spawned by drug trafficking. Nevertheless, the novel's deviation from the model validates its ethical dimension: drug

\footnotetext{
* Este artículo forma parte del Proyecto de Investigación Fondecyt № 1190475 "A punta de balas y excesos: marginalidad social y literaria en la nación neoliberal en narcorrelatos chilenos del siglo XXI", a cargo del Dr. Danilo Santos y del cual soy Investigadora externa asociada.

** Doctora en Literatura. Académica del Colegio de Letras Hispánicas, Facultad de Filosofía y Letras, UNAM, Ciudad de México, México. Correo electrónico: ainhoavasquez@filos.unam.mx. Orcid: https://orcid.org/0000-0002-7747-8606.
} 
traffickers are not romanticized, but rather are represented as ruthless criminals and, despite the fact that the detective is disillusioned with the political system, an assurance in the existence of honest people prevails. These elements, therefore, position the work as an antecedent of narco-narrative, while at the same time differentiating it by its critical stance towards the phenomenon of drug trafficking.

KeYwords: Narco-literature, detective fiction, Ramón Díaz Eterovic.

Recibido: 19.04.2019. Aceptado: 01.04.2020

\section{INTRODUCCIÓN}

Colo en la oscuridad (1992) del escritor chileno Ramón Díaz Eterovic $\checkmark$ es la segunda novela protagonizada por el ya reconocido detective Heredia, luego de su aparición en La ciudad está triste (1987), en que se relata la búsqueda de los restos de detenidos desaparecidos, durante la dictadura militar. La segunda obra, no obstante, es una novela policial, cuyo eje son las redes internacionales del narcotráfico, antes de su identificación como el nuevo género literario que se ha dado en llamar narcoliteratura. Antes de La virgen de los sicarios (1994) de Fernando Vallejo o de Un asesino solitario (1999) de Élmer Mendoza -novelas consideradas inaugurales de este modelo- y mucho antes también de la multicitada polémica entre Rafael Lemus y Eduardo Antonio Parra en las páginas de la revista Letras Libres (2005), en torno a la calidad y pertinencia de la temática del narcotráfico en la literatura del norte de México ${ }^{1}$, Ramón Díaz Eterovic ya lo había narrado.

Hoy, no resulta extraño encontrar los escaparates de las librerías latinoamericanas -e incluso norteamericanas y europeas- atestadas de literatura sobre el narcotráfico. La narcoliteratura se ha convertido en un fenómeno editorial, quizá comparable al boom del realismo mágico, según académicos como Diana Palaversich (2011) o Mauricio Zabalgoitia (2010). Esa literatura que romantizaba el exotismo de Latinoamérica y revelaba una magia escondida en cada rincón de sus poblados, hacia fines del siglo XX y principios del XXI, fue cambiada por un nuevo "espacio de aventura y exotismo renovado por el narcotráfico” (Zabalgoitia, 2010, p. 430). Los sombreros de pana fueron reemplazados por los vaqueros, las ojotas por cuero

\footnotetext{
${ }^{1}$ La polémica empieza con el artículo "Balas de salva. Notas sobre el narco y la narrativa mexicana" de Rafael Lemus. Eduardo Antonio Parra responde publicando "Norte, narcotráfico y literatura", ambos en Letras Libres (2005). Para una explicación detallada de la polémica y análisis de las primeras obras de la narcoliteratura, véase Felipe Oliver (2013) y Ramón Gerónimo Olvera (2013).
} 
de cocodrilo y lo maravilloso fue asesinado por balas de AK47. Ello trajo exitosos resultados comerciales:

La maquinaria mercadotécnica de conglomerados editoriales como Planeta, Alfaguara, Mondadori y Tusquets, entre otros, que en los últimos años de los años noventa "descubrieron" la literatura del norte como el nuevo sabor de la literatura mexicana, comienzan a empaquetar para la venta tanto doméstica como trasnacional la narconarrativa mexicana como la más reciente expresión de la exótica barbarie latinoamericana. (Palaversich, 2011, p. 55) ${ }^{2}$

Aunado a esta polémica respecto a su constitución como moda editorial, lo narco comenzó a pensarse como un nuevo subgénero o género narrativo. Así, mientras Gustavo Forero (2012), Joachim Michael (2013) y Arturo García Niño (2013) propusieron abordarlo como un subgénero de la literatura policial, con Danilo Santos e Ingrid Urgelles (2016) optamos por calificarlo como un género narrativo $y$, por ello, con reglas propias. Para la revista española Mitologías Hoy, elaboramos una primera tipología que, posteriormente, hemos ido ampliando sobre la base de rasgos narratológicos que compartirían estas novelas y que nos permitirían afirmar que estamos ante un género literario: un narrador autodiegético que establece un pacto de lectura con el lector; espacios fronterizos y precarios, símil de las condiciones sociales de los personajes; una atemporalidad circular, por cuanto resulta imposible escapar de la violencia; personajes fijos, como capos, sicarios, burócratas de la industria, policías, detectives y víctimas; una estilística gore y estética traqueta ${ }^{3}$, así como la revelación de un Estado criminal que propicia este tipo de crimen.

Hemos apostado desde entonces que la narcoliteratura no es un subgénero de la novela policial, sino un género narrativo propio. Para ello hemos recurrido a la definición otorgada por Todorov (1988), en su texto "El origen de los géneros", en el cual explica que todos los géneros literarios se encuentran en constante transformación, es decir, que cada cierto tiempo surgen nuevos, producto de la inversión, el desplazamiento o la combina-

\footnotetext{
${ }^{2}$ Heriberto Yépez (2014) propone una lectura contrapuesta sobre este fenómeno editorial. Para él, escribir narcoliteratura es responder a las condiciones sociales del México actual y no a un éxito de mercado, puesto que este tipo de novelas no tiene ventas mayores que otros géneros ni hay evidencia de que los narcoliteratos tengan mayor éxito con lectores, críticos o colegas. Nada haría suponer que su afán es meramente comercial.

${ }^{3}$ En Colombia, se denomina "traqueto" a los narcotraficantes. Por "estética traqueta" se entiende la moda específica de los capos, basada en la ostentación de sus lujos y su dinero.
} 
ción con otros. Ello dependerá del contexto político-social en que se creen o modifiquen, puesto que cada sociedad elige y codifica los actos que corresponden a su ideología para convertirlos en género. De esta manera, la narcoliteratura podría pensarse como una reconversión o modificación de la novela policial, pero que se rige por rasgos autónomos, vinculados a un momento político, social y económico determinado.

Su instauración y bautizo como género literario se da, así, producto de un contexto específico: la guerra contra el narcotráfico en Colombia y México en los primeros años del 2000, sin embargo, desde algunos años antes se fueron creando las condiciones políticas y sociales para que ello ocurriera. El narcotráfico, como industria, empezaba a despuntar y a revelarse como un problema transnacional que también afectaba a Sudamérica ${ }^{4}$. Es en este período que Ramón Díaz Eterovic publica Solo en la oscuridad, una novela policial pero que, a la luz de las investigaciones sobre la narcoliteratura, hoy podríamos leer como un antecedente: una obra bisagra entre lo policial y el narco, que anticipaba el nuevo género que se convertiría en boom.

La apuesta de este artículo, por lo tanto, es analizar esta novela de Díaz Eterovic más allá de la literatura policial y delimitar ciertos rasgos que compartiría con el género de lo narco: estética traqueta, personajes femeninos víctimas, ciertas descripciones despiadadas que colindan con el gore y la visibilización de redes transnacionales en el lucrativo negocio. Posteriormente, identificar aquellos elementos que la diferencian de la narcoliteratura: los criminales no son víctimas, los sicarios son ineptos y, a pesar del desencanto del detective por la realidad en que le ha tocado vivir, no denuncia un Estado criminal, sino un gobierno ineficaz, pero en el que aún hay gente honesta.

Enfatizar las diferencias entre la novela de Díaz Eterovic y la narconarrativa responde a la impresión de que nos encontramos ante una novela antecedente, un policial narco que diverge del actual género al constituirse en un texto censor del crimen organizado y de sus redes transnacionales, sin el exotismo y la romantización que los académicos ven en estas obras recientes. Solo en la oscuridad examina el problema de las drogas para denunciar que será un asunto de primera importancia para los gobiernos latinoamericanos, a la vez que lo visualiza desde la mirada de un detective recto que lucha contra una industria criminal. En este sentido, esta novela se enmarcaría en una narrativa sobre el narcotráfico, previa a su clasifica-

\footnotetext{
${ }^{4}$ En el artículo "Apropiación cultural de lo narco en Chile: la narcoserie Prófugos" (2017), he realizado un repaso por la historia del narcotráfico en Chile y sus vínculos internacionales.
} 
ción como narcoliteratura, con la cual comparte características y, a la vez, disiente por su dimensión crítica y ética.

\section{SOLO EN LA OSCURIDAD: RASGOS DE UNA NARCOLITERATURA}

La historia comienza una noche cualquiera, en que Heredia conoce a Laura, una aeromoza ebria y asustada, a quien el detective lleva a su departamento para protegerla. Al día siguiente, ella será asesinada en su hotel y él deberá cumplir con lo que le ha pedido: ir al banco y abrir una caja de seguridad con dinero y cartas. Empezamos, entonces, a conocer la vida de la azafata y a reconstruir su misteriosa trama. Laura ha estado casada con un narco argentino, Gastón Muleiro, con quien tiene una hija. Aprovechándose del trabajo de la mujer, el traficante la obliga a transportar droga y dinero en cada uno de sus viajes. Laura es víctima de su ex pareja que la ha convertido en un tipo de "burrera".

En la jerga del narco, se entiende por "burrera" (o "mula") a cualquier mujer que se dedica al traslado de mercancía ilegal, de una frontera a otra (Maihold y Sauter, 2012). Muchas de ellas utilizan su propio cuerpo para realizar esta empresa, tragando cartuchos rellenos de cocaína o heroína, corriendo un alto riesgo para su salud (recordemos la aclamada película María, llena eres de gracia (2004), por ejemplo) ${ }^{5}$. Laura lo hace con mayor facilidad debido a su empleo, sin embargo, los tentáculos del narcotráfico son múltiples y Heredia sospecha que su asesinato responde a un fallo en la última operación que le fue encomendada, deducción que realiza al encontrar una carta escrita por Muleiro:

Llevarás un paquete a Santiago y en vez de guardarlo en la caja de seguridad de costumbre, arrendarás otra en el banco que quieras. Te aseguro que no corrés riesgos. La gente con la que trabajo esperará el depósito y cuando sospechen algo, estaré muy lejos. (Díaz Eterovic, 1992, p. 58)

Tanto en las ficciones como en las investigaciones periodísticas que se han realizado en torno a la participación de las mujeres en el narcotráfico, el sujeto femenino es representado, comúnmente, como víctima. Las mujeres nunca ingresan en el narcomundo por opción propia, sino que lo hacen motivadas por necesidades económicas apremiantes o porque son

\footnotetext{
${ }^{5}$ Según un análisis realizado por Erika Sánchez Ríos (2017), ser burreras es el rol más común de los personajes femeninos en las narcotelenovelas actuales.
} 
obligadas o persuadidas por hombres cercanos a ellas: las protagonistas de novelas como La reina del sur (2002) de Arturo Pérez-Reverte y Perra brava (2010) de Orfa Alarcón, lo hacen por amor a sus novios narcos, mientras en Las mujeres matan mejor (2013) de Omar Nieto, la protagonista se involucra en ello luego de que han asesinado a su pareja. En el caso de Laura, sabemos que, además, realiza este trabajo por amor a su hija, ya que Muleiro la ha amenazado: "Estoy desesperado, Laura, así que no te negués a lo que pido. De lo contrario volveré a Santiago y de seguro te acordarás cómo soy cuando me embronco. Pensá en nuestra nenita" (Díaz Eterovic, 1992, p. 58).

Algo similar ocurre con Mónica Adrián, la novia del narco argentino, quien también se ve envuelta en el narcotráfico por amor. Como dependienta del negocio de libros, ayuda a que el criminal engañe a su socio, el dueño de la librería, para robarle una gran cantidad de dinero. Muleiro es victimario tanto de Laura como de Mónica, lo que concuerda con el estereotipo femenino, elaborado por la narconarrativa y los estudios periodísticos (Ovalle y Giacomello, 2006; Jiménez Valdez, 2014). Víctimas, carne de cañón, las mujeres son las más expuestas a ser apresadas o asesinadas, tal como lo demuestra un estudio realizado por Edith Carrillo Hernández (2012) en la cárcel mexicana de Puente Grande de Jalisco:

Los esquemas genéricos inciden en que las mujeres suelen aceptar o coadyuvar a que sus parejas o hijos realicen este tipo de actividades o consumo. Entre las razones para explicar esta decisión están el temor a ser abandonadas, el escaso poder para intervenir en la situación que vivían y la obediencia o resignación al considerar que no había otra alternativa más que aceptar lo decidido por sus esposos o hijos, y por la creencia de que debían sacrificarse por "amor". (pp. 69-70)

Laura y Mónica podrían ser personajes de cualquier narconarrativa actual, en la medida en que son construidas como sujetos víctimas de un hombre narcotraficante, no obstante, al contrario de las producciones recientes, en que, a pesar de ser vulnerables se las criminaliza, Heredia las exculpa. A Laura, porque reconoce que su motivación responde a la necesidad de proteger a su hija: "La causa de su participación se entendía en la carta, y ante eso no existía ley para juzgarla” (Díaz Eterovic, 1992, p. 58). Y a Mónica, porque escucha y comprende la violencia que ella ha sufrido por parte de Muleiro: "Su cariño parecía sincero, pero me equivoqué. Gastón contaba con una amiga que le traía desde Chile cierta mercadería. Deseaba saber quién era, le pedí explicaciones y solo conseguí sus golpes" (p. 107). Heredia se distancia de la actual narconarrativa, pues no solo las justifica, 
sino que busca justicia por ellas. Al contrario de telenovelas y novelas recientes, en que las mujeres que resultan asesinadas por involucrarse en el crimen organizado terminan en basureros públicos, sindicadas como N.N. y sin nadie que siquiera las llore, el detective se empeña en encontrar a los responsables y hacer pagar a Gastón Muleiro, principalmente, por el asesinato de Laura.

Otro de los rasgos propios de la narcoliteratura es la estética traqueta, la que ya hemos señalado con Danilo Santos e Ingrid Urgelles (2016). Mansiones de lujo, autos del mes, cadenas de oro y trajes de seda, son elementos recurrentes en las narraciones del narcotráfico, un derroche excesivo que ha traído la asunción de una nueva moda, como lo indican Abad Faciolince (2008) o Alberto Fonseca (2016), para el caso colombiano. De esta forma, mientras los narcotraficantes en Colombia ostentan "carros, fincas, cemento, caballos, edificios estridentes, música ruidosa, teléfonos celulares" (Abad Faciolince, 2008, p. 513) y los mexicanos se construyen mausoleos apoteósicos en el panteón Jardines del Humaya; los narcotraficantes de Díaz Eterovic se mueven en autos que "vale[n] más de lo que le paga a su jefe por sus mentiras de un año" (Díaz Eterovic, 1992, p. 207) y habitan esos edificios estridentes que refiere Abad Faciolince: "El dinero era tan evidente en las oficinas de Garcimuñoz que, si uno era un pobre diablo a mitad de una tarde cualquiera, no entraba en ellas ni perseguido por un toro furioso" (Díaz Eterovic, 1992, p. 207).

Como han referido Guillermo García-Corales y Mirian Pino (2002), especialistas en la obra de Ramón Díaz Eterovic, esta estética del derroche del narcotráfico tendría su correlación directa en la imagen de la ciudad deteriorada producto del neoliberalismo, que no solo se presenta en esta novela sino en todas las aventuras de Heredia. A menudo el detective, en su deambular por Santiago, descubre a los niños que viven en condiciones precarias debajo de los puentes, mendigos recolectando cartones y oficinistas de trajes desgastados. En contraste con esta realidad, permanecen los sueños capitalistas de los ciudadanos, con la necesidad de ser parte del mercado comercial y poder consumir lo que se les ofrece: "Cuando observa a los 'otros' frente a las vitrinas y sus 'chucherías', el investigador acude a una sentencia metafórica para calificar el sentido de identidad ciudadana consumista que domina a la ciudad: 'casi todo el mundo, estaba convertido en un tragamonedas"' (García-Corales y Pino, 2002, p. 97).

Contrapuntos que Heredia explora constantemente: la decadencia de la ciudad, la pobreza de sus calles y de sus habitantes, mientras se refleja la ilusión de los ciudadanos de ingresar en el mercado capitalista y poder 
consumir sus productos. Una fantasía que se convierte en realidad en esta novela, pero a costa de un negocio ilícito y del que Díaz Eterovic realiza una crítica. Si para ingresar al paraíso prometido del capitalismo y poder ostentar carros y edificios estridentes hay que asesinar, robar y traficar, es mejor seguir el ejemplo de Heredia y vivir modestamente. Tal como apuntan García-Corales y Pino (2002), el detective, censor de la ostentación de los lujos de la editorial vinculada al narcotráfico, se enorgullece, en cambio, de su precariedad, de su viejo Fiat 600, su departamento arrendado en un barrio marginal en Santiago, sus libros y su gato. En esta modestia hay signos de su anticorrupción al sistema neoliberal.

Así, la narcoliteratura actual exhibe con detalle el modelo capitalista como ejemplo y los narcotraficantes se retratan como exitosos desde sus posesiones materiales, reflejando:

la emergencia de una nueva escala de valores en la que el dinero fácil y el consumo de mercancías controlan la manera en que los individuos reaccionan frente al futuro y dialogan con los valores de la sociedad tradicional como el esfuerzo, el trabajo y el estudio. (Fonseca, 2016, p. 8)

Díaz Eterovic, en cambio, a través de su detective Heredia, representa el viejo paradigma de la humildad en el que la ética está primero y jamás se transa la moral.

Finalmente, debemos indicar que la novela de Díaz Eterovic fue pionera en el hecho de develar el tema del crimen organizado como un asunto transnacional. Hoy, es bastante común, principalmente en las narcotelenovelas, producidas por grandes cadenas internacionales, mostrar al narcotráfico como un proceso industrial que comienza con la plantación en países como Bolivia y Colombia, que necesita de naciones de tránsito y exportación como México, para llegar a los receptores estadounidenses. Sin embargo, el novelista chileno agrega el Cono Sur como lugar de transporte y consumo, una realidad presente ya en estos años (Vásquez, 2017).

Las ciudades de Santiago y Buenos Aires develan también la transnacionalidad de un negocio ilícito tremendamente lucrativo. Así, a la par de exhibir una imagen deteriorada de ciertos espacios citadinos marginados por el neoliberalismo, las capitales también se convierten en centros neurálgicos para el desarrollo de una industria criminal. La miseria de la periferia, producto de las políticas gubernamentales capitalistas, es la que propicia el surgimiento de estos negocios ilegales de carácter internacional. El narco- 
tráfico como industria, entonces, se sitúa en la médula de las ciudades, y sus agentes (capos, sicarios, transportistas) se ocultan bajo el traje cosmopolita empresarial (Ovalle, 2010).

En la novela de Díaz Eterovic los narcotraficantes se esconden en las capitales de Chile y Argentina, bajo la apariencia de empresarios honestos. Romera, por ejemplo, es el dueño de la librería Moby Dick de Buenos Aires, sin embargo, utiliza la librería como fachada para guardar paquetes de droga que vienen desde Colombia y Chile. Laura, como aeromoza, está en una posición privilegiada para servir de transportista de la mercancía. Sosa es un abogado reconocido, pero, a la vez, es uno de los pilares del negocio del narcotráfico en Argentina. Todo ello se descubre gracias a la intervención de Heredia en Buenos Aires, permitiendo que se desestabilice, al menos, la parte argentina del negocio: "Lo concreto es que la policía desbarató una red de traficantes conectados con el cartel de Medellín. Atraparon a un tal Romera y al financista del grupo, un abogado de apellido Sosa" (Díaz Eterovic, 1992, p. 157).

En Chile el asunto es similar. Garcimuñoz es un editor de prestigio y dinero, no obstante, dentro de la red, es el encargado de registrar los embarques de la droga, así como de la distribución desde Buenos Aires a Santiago. El poeta Ferrada es uno de los últimos en involucrarse en la industria, engañado con la promesa de que lo publicarán si se une a las filas. Es Ferrada, finalmente, el responsable directo de la muerte de Laura, por temor a que le devele a Heredia las conexiones internacionales que operan en el narcotráfico.

La ubicación del crimen en las capitales sudamericanas, sus agentes ocultos en profesiones de respeto, y la facilidad en el transporte y distribución de la mercancía ilegal, demuestran que el negocio del narcotráfico, como asegura Ovalle (2005), se ha convertido en una industria poderosa propiciada por la globalización y la internacionalización de sus redes, "gracias al incremento en la circulación de capitales, información y personas a escala mundial" (pp. 121-122). Ante ello, resulta lógico que Heredia reflexione sobre el peligro que ha corrido al enfrentarse a esto:

Los responsables de la muerte de Laura Suárez no eran una tropa de aficionados, y yo, torpemente, había salido a sus calles con la misma lógica que acostumbraba a usar con los maridos que castigaban más de la cuenta a sus mujeres, o al buscavidas atrasado en el pago de una deuda. (Díaz Eterovic, 1992, p. 141) 


\section{CIERTAS DIFERENCIAS CON LA NARCONARRATIVA}

Aunque, como hemos venido señalando hasta acá, la novela de Díaz Eterovic puede leerse como narcoliteratura, producto de ciertos rasgos que comparte con este género, el tratamiento que el autor realiza respecto al narcomundo resulta muy diferente al que hoy acostumbramos ver y leer en México y Colombia o, incluso, en las nuevas manifestaciones argentinas y chilenas. La primera distancia resalta en el protagonista. Si bien, según lo que hemos propuesto con Santos y Urgelles (2016), es común que policías y detectives sean personajes principales en la narcoliteratura, éstos, generalmente, fungen como agentes de los cárteles, amigos de los narcotraficantes o, en el mejor de los casos, como perseguidores motivados por venganzas personales y no por verdadero deseo de justicia.

Desde El señor de los cielos, la narcoserie con más rating y temporadas hasta ahora, la representación del detective es ambigua: Marco Mejía, el policía que persigue a Aurelio Casillas en la primera temporada, busca venganza por la muerte de su padre. Leonor Ballesteros, la persecutora que sucede a Mejía, se involucra sentimentalmente con el capo. Y en las novelas de Élmer Mendoza, el apodado "padre de la narcoliteratura mexicana", su detective "Zurdo" Mendieta se convierte en aliado involuntario del Cártel de Samantha Valdés hasta el punto que en Besar al detective (2015) es removido de su cargo, porque la ayuda a escapar de un hospital. Los detectives y policías de la narconarrativa están muy lejos de la moral intachable de Heredia, quien se ha propuesto no descansar hasta encontrar a los culpables de la muerte de Laura y hacer justicia por ella. A tal grado llega su ética que, a pesar de sentir cierto cariño por Ferrada, en el momento en que descubre que él es el asesino de la aeromoza, va en su búsqueda, dispuesto a apresarlo.

A esta primera divergencia, sumamos la caracterización que se hace de otro de los personajes recurrentes en estas narraciones: los sicarios ${ }^{6}$. Tal como se han venido representando desde la novela de Fernando Vallejo (1994), se definen por su apatía y su sangre fría a la hora de cometer crímenes. A pesar de que cumplen órdenes, son sumamente sanguinarios $\mathrm{y}$, muchos de ellos, asesinan por placer antes que por mandato. Jamás fallan, al contrario de los sicarios ineptos de Solo en la oscuridad. En Buenos Aires, Uriarte debe espiar a Heredia y detener sus investigaciones, sin embargo, es

\footnotetext{
${ }^{6}$ El término refiere a asesinos a sueldo, generalmente, personas de bajos recursos que ven en este trabajo una oportunidad de ascenso económico.
} 
él quien lo descubre. Luego, se le encarga asesinar al detective atropellándolo, pero no consigue más que causarle un rasguño en el traje. Muy lejos de la imagen tradicional de sicarios armados, listos y efectivos, Uriarte se revela como un hombre gordo, incompetente, incluso cercano a lo ridículo: "El gordo no valía nada. Era un ganapán de tercera clase, incapaz de ejercer su oficio con un poco de dignidad" (Díaz Eterovic, 1992, p. 114).

Algunas páginas más adelante, Sosa, el abogado involucrado en las redes del narcotráfico, nuevamente manda a asesinar a Heredia, pero sus sicarios también fracasan. En lugar de cumplir con las órdenes de sus superiores, se distraen con unas prostitutas, permitiéndole al detective dispararle en la sien a uno y lanzar al río al otro: "lanzó un puñetazo débil y repetí mi castigo hasta que lo vi perder el equilibrio y caer en las aguas turbias del río. Contemplé sus esfuerzos por mantenerse a flote, y enseguida busqué la salida del puente" (Díaz Eterovic, 1992, p. 138). Heredia sale ileso de los dos ataques de los sicarios, mientras los matones son los perjudicados. Una imagen grotesca si la aparejamos a los sicarios de El señor de los cielos, el ejército mara que protege a Víctor Casillas, por ejemplo. Incluso bufonescos, en comparación a la eficiencia de los sicarios de Samantha Valdés que encuentran al hijo de Mendieta en Besar al detective (2015).

A la par de esta manera risible de presentar a los sicarios, agregamos también un perfil diferente de los narcotraficantes. Resulta un recurso común en la narconarrativa enfatizar la precariedad de quienes se involucran en el narco. Escobar, "El Chapo" o Carrillo Fuentes, han sido personajes recurrentes en narcoseries que recrean su vida desde la niñez, en poblados mexicanos periféricos, para resaltar la fortaleza y valentía de estos individuos al salir de la pobreza. En ello radica la principal crítica a estos productos, que en pos de mostrar la lucha por la supervivencia de aquellos que viven en la miseria, los enaltecen como un modelo a seguir. En palabras del colombiano Omar Rincón (2013):

Historias que justifican, argumentan y exculpan el cómo se llega a ser narco o mujer de silicona o violento matón; épicas melodramáticas y cómicas (¡el humor no puede faltar en lo popular!) que celebran los métodos paralegales para ascender socialmente: narrativa que celebra el triunfo express expresado en billete, armas, trago, mujeres-sexo. (p. 21)

Enfoque disidente, por cuanto, en las narconarrativas actuales se apunta a idealizar el escape de la pobreza, mientras Díaz Eterovic dirige su crítica hacia la ambición. Coherente con esta orientación, en el recorrido, la narcoliteratura y las narcoseries exaltan también rasgos que se consideran 
positivos: los capos tendrían ciertos códigos morales, como no asesinar a los familiares de los enemigos, ayudar económicamente a su pueblo, construir comedores populares y orfanatos, por poner algunos ejemplos. Los narcos de Solo en la oscuridad, al contrario, son individuos que se mueven por la avaricia, sin códigos, sin ética y que no actúan por una genialidad individual, sino en cadenas de producción criminal. Al develar las redes internacionales del narcotráfico y mostrar los diferentes aspectos profesionales que pueden adoptar como fachadas, Díaz Eterovic recalca la ambición del ser humano corrupto sin romantizar el hecho de salir de la pobreza. Los narcotraficantes son criminales profesionales, peligrosos, ávidos de dinero y poder.

Estas conexiones transnacionales que Díaz Eterovic exhibe, si bien operan gracias a la apatía e ineficiencia de sistemas políticos que las permiten, a diferencia de las narconarrativas recientes, no se producen en complicidad con el Estado. Tal como ha investigado Héctor Domínguez Ruvalcaba (2015) para el caso mexicano y Gustavo Forero (2012) para el colombiano, uno de los rasgos más relevantes de la narcoliteratura es la representación del Estado como criminal, como el culpable de la violencia, de las desigualdades y de la impunidad. Domínguez Ruvalcaba refiere que la literatura sobre crimen organizado se enfocaría:

(...) en la descomposición de la estructura oficial en la medida en que varios personajes de historias criminales son también parte del aparato gubernamental, lo que pone en duda la efectividad del Estado. El vínculo entre representantes del gobierno y los grupos criminales establece un sistema de impunidad e inseguridad, lo que ha de entenderse, más que como una falla del Estado, como un sistema político y económico que se vale de la violación de la ley para constituirse. (p. 119)

Es indudable que la novela de Díaz Eterovic presenta también un grado alto de escepticismo frente a las instituciones neoliberales, heredadas del gobierno militar, lo que se manifiesta en la incorporación de personajes narcotraficantes vinculados al poder. Cañadas, por ejemplo, es agente del servicio de seguridad del Ejército: "Cañadas y su grupo traficaban cocaína a diestra y siniestra. Incluso se dice que con las utilidades crearon una financiera clandestina que reunía dinero entre los militares" (Díaz Eterovic, 1992, p. 172). Sin embargo, la criminalidad no arrasa con el Estado en su totalidad. Heredia todavía tiene amigos en quienes puede confiar y con quienes colaborar.

En Argentina, Heredia contribuye a que el comisario Morón detenga la 
red criminal bonaerense: "Con tus datos conseguimos atrapar a Sosa. Pensaba huir al Brasil cargando un bulto de pasta. Lo hicimos hablar y ahora estamos en condiciones de romper una importante red de narcotráfico" (Díaz Eterovic, 1992, p. 143). A cambio, Morón le da los nombres de los contactos del abogado Sosa en Chile, lo que permitirá desmantelar esa parte: Atilio Cañadas, Federico Arraño y Andrés Garcimuñoz. También le ofrece una unidad policial para que pueda turistear por Buenos Aires. Y en Chile, Heredia tiene a Solís, su gran aliado: "Debes ser el único policía honesto de la ciudad (...) una especie condenada a la extinción” (Díaz Eterovic, 1992, p. 166). Frente a la desconfianza absoluta de un Estado criminal en las narconarrativas actuales, Heredia todavía puede guardar esperanza en ciertos elementos institucionales. No todo ni todos han sido corrompidos ${ }^{7}$.

Por si ello no fuera suficiente, si aun no confiamos en la justicia, en la novela de Díaz Eterovic permanece la mano dura del melodrama, imponiendo la muerte a todos los criminales. Este final resulta coherente con la personalidad individualista y ambiciosa con que los narcos son representados, puesto que, al no existir códigos entre ellos, quedan desnudos frente a tanta violencia: "Después de todo ha sido un caso fácil. Había mucha desconfianza entre los involucrados y terminaron ahogándose en su propio fango" (Díaz Eterovic, 1992, p. 223). Gastón es asesinado por órdenes del editor. Cañadas es asesinado también, incluso Arraño es asesinado, por casualidad, por el mismo Heredia. Ferrada se suicida:

lo vi caer desde lo alto y estrellar su cuerpo contra las rocas. El mar lo arrastró hacia su interior y lo perdí de vista. Volví a verlo dos días más tarde. El mar lo había devuelto a la tierra. Su rostro estaba hinchado y los peces le habían comido los ojos. (Díaz Eterovic, 1992, p. 223)

También del lado del gobierno, aún existen personas como Heredia, para quienes no todo vale para salir de pobre y que no tienen precio. $\mathrm{Pu}-$ eden ser pocos, pero ellos son los que mantienen la esperanza en la recomposición del tejido social. Y, si el Estado falla en la impartición de justicia, el destino melodramático igualmente alcanza a los criminales para hacerlos pagar con muertes que colindan con lo gore (baste releer la descripción del cadáver de Ferrada, por ejemplo). Estas muertes, no obstante, también se diferencian del gore de los productos narcoculturales, en cuanto su fin no

\footnotetext{
${ }^{7}$ Como indica José Promis (2005): “quizás sus rasgos psicológicos más importantes sean su altruismo y su fe indestructible en la justicia, aun a pesar de estar convencido de que la justicia anda por otro lado" (p. 163).
} 
es estético, de banalización o de espectacularización de la violencia, sino el castigo que deben recibir quienes han quebrado los límites sociales. El asesinato de Laura, al fin, es resuelto y resarcido.

\section{CONCLUSIONES}

El objetivo de este artículo ha sido el de visibilizar los rasgos que comparte la segunda novela de Ramón Díaz Eterovic (Solo en la oscuridad, 1992) con las recientes narconarrativas, con el fin de demostrar que estamos ante un antecedente de estas, una obra intermedia entre el neopolicial y la actual narcoliteratura. A esta novela podemos agregar otra novela precursora, $\mathrm{La}$ ciudad (1963) de Alfredo Gómez Morel, la que según ha señalado en varios congresos Felipe Oliver (2013), es realmente la primera narconovela latinoamericana, por cuanto se presenta el narcotráfico como una red transnacional en la que se incluyen chinos, peruanos y chilenos. Rastrear los antecedentes de este nuevo modelo permite entender, siguiendo a Todorov, de qué forma se van modificando los géneros según los contextos políticos y sociales en que emergen. En ello radica la importancia de este ejercicio.

Como antecedente, sin embargo, Solo en la oscuridad comparte algunos rasgos de la narconarrativa, a la vez que difiere en otros aspectos. Las mujeres son estereotipadas en el rol de víctimas, pero ello no implica que sean criminalizadas por el detective. Al contrario de las mujeres involucradas en el narco, que en las narconarrativas contemporáneas terminan asesinadas y desechadas en basurales o desiertos, Heredia busca hacer justicia por Laura. Asimismo, hay una estética traqueta y una revelación de las conexiones internacionales del narcotráfico, pero ello está al servicio de enrostrar las fallas del sistema neoliberal, que ha impulsado una lucha por la adquisición de bienes sin medir las consecuencias. De la mano con esto, se desliga de la narcoliteratura actual para representar la ambición de los narcotraficantes sin romantizar su pobreza de origen. Y, aunque existen vínculos de ciertos agentes del Estado con el crimen organizado, éstos no han permeado por entero a las instituciones.

La principal distancia entre la pionera novela de Díaz Eterovic y la narcoliteratura reciente, así, es el cariz ético entre ambas representaciones del narcotráfico. Diana Palaversich (2011) ya había notado esta diferencia entre las primeras manifestaciones mexicanas y las actuales, que intentan responder mayormente a las exigencias del mercado editorial internacional. En este sentido, toma como ejemplo Contrabando (2008) de Víctor Hugo Rascón Banda, escrita en 1991, pero publicada después de su muerte, a 
la que considera "una obra visionaria que presenta al narcotráfico como una tragedia griega de proporciones épicas [,] donde las causas sociales, culturales e históricas de la violencia se entretejen con el destino trágico y universal del ser humano" (p. 61).

La propuesta de Palaversich es que la gran narrativa sobre el narcotráfico se produjo antes del fenómeno editorial, puesto que en un primer momento, la intención de los autores era reflexionar sobre las causas y consecuencias de la irrupción del crimen organizado en Latinoamérica, mientras que hoy se anteponen los intereses económicos de las editoriales. Es por ello que Palaversich (2012) incluye el elemento ético, entendido como:

la responsabilidad personal y el compromiso moral que asume un autor ante el momento histórico que vive y el tema que narra, y cuyo resultado es una obra que tiene un profundo impacto en el lector y contribuye a la comprensión del predicamento existencial y del sufrimiento del otro (s.p.)

Aunque Díaz Eterovic no involucra, como Rascón Banda, las razones históricas de la violencia, sí procura un tratamiento humano hacia las víctimas del narcotráfico y, en ese sentido, busca justicia para Laura. Asimismo, su novela resulta ética por cuanto visibiliza, como pocas, el problema del crimen organizado desde una perspectiva transnacional y compleja. El narco sería una consecuencia de los sistemas capitalistas que han provocado segregaciones sociales y económicas, infundiendo ambiciones irracionales en los ciudadanos; a la vez que en Chile es resultado de la implementación de las políticas neoliberales heredadas de la dictadura.

Sin romantizar, victimizar ni exotizar a los asesinos, el escritor chileno devela las redes criminales, la falta de empatía y una sociedad corrompida. En ello radica su ética y su compromiso como escritor, y por esto no resulta extraño que se haya adelantado en la temática a este boom editorial: Díaz Eterovic observa con suspicacia, entiende, exhibe y critica dónde estamos y hacia dónde vamos, como país y como humanidad.

\section{REFERENCIAS}

Abad Faciolince, H. (2008). Estética y narcotráfico. Revista de Estudios Hispánicos 42(3), 513-518.

Alarcón, O. (2010). Perra brava. Ciudad de México, México: Planeta.

Carrillo Hernández, E. (2012). ¿Vinculadas al narco? Mujeres presas por delitos contra la salud. Desacatos 38, 61-72. 
Díaz Eterovic, R. (1992). Solo en la oscuridad. Santiago, Chile: Lom.

Díaz Eterovic, R. (1987). La ciudad está triste. Santiago, Chile: Lom.

Domínguez Ruvalcaba, H. (2015). Nación criminal: narrativas del crimen organizado y el Estado mexicano. Ciudad de México, México: Ariel.

Fonseca, A. (2016). Cuando llovió dinero en Macondo: literatura y narcotráfico en Colombia y México. Sinaloa, México: Universidad de Sinaloa.

Forero, G. (2012). La anomia en la novela de crímenes en Colombia. Medellín, Colombia: Universidad de Antioquia.

García-Corales, G. y Pino, M. (2002). Poder y crimen en la narrativa chilena contemporánea. Las novelas de Heredia. Santiago, Chile: Mosquito Editores.

García Niño, A. (2013). La narconarrativa un subgénero literario fronterizo y binacional. Razón y palabra 84, 1-21.

Gómez Morel, A. (1963). La ciudad. Santiago, Chile: Renacimiento.

Jiménez Valdez, E. (2014). Mujeres, narco y violencia: resultados de una guerra fallida. Región y sociedad 4, 101-128.

Lemus, R. (2005). Balas de salva. Notas sobre el narco y la narrativa mexicana. Letras Libres 81, 39-44.

Maihold, G. y Sauter, R. (2012). Capos, reinas y santos. La narcocultura en México. iMex. México Interdisciplinario 3, 64-96.

Mendoza, E. (1999). Un asesino solitario. Ciudad de México, México: Tusquets.

Mendoza, E. (2015). Besar al detective. Ciudad de México, México: Penguim Random House.

Michael, J. (2013). Narco-violencia y literatura en México. Sociologías 15(34), 44-75.

Nieto, O. (2013). Las mujeres matan mejor. Ciudad de México, México: Joaquín Mortiz.

Oliver F. (2013). Apuntes para una poética de la narcoliteratura. Guanajuato, México: Universidad de Guanajuato.

Olvera, R.G. (2013). Solo las cruces quedaron. Literatura y narcotráfico. Ciudad de México, México: Ficticia.

Ovalle, L. y Giacomello, C. (2006). La mujer en el "narcomundo". Construcciones tradicionales y alternativas del sujeto femenino. La ventana 3(24), 297-319.

Ovalle, L. (2005). Las fronteras de la "narcocultura". La frontera interpretada. Procesos culturales en la frontera noroeste de México (pp. 117-150). Mexicali, México: Universidad Autónoma de Baja California.

Ovalle, L. (2010). Narcotráfico y poder. Campo de lucha por la legitimidad. Athenea digital 17, 77-94.

Palaversich, D. (2011). Narcoliteratura (¿De qué más podríamos hablar?). Tierra adentro $167,54-63$.

Palaversich, D. (2012). ¿Cómo hablar del silencio?: “Contrabando" y "Un vaquero cruza la frontera en silencio", dos casos ejemplares del acercamiento ético en la literatura mexicana sobre el narco. CiberLetras: revista de crítica 
literaria y de cultura 29, http://www.lehman.edu/faculty/guinazu/ciberletras/v29/palaversich.html\#6

Parra, E. A. (2005). Norte, narcotráfico y literatura. Letras Libres 82, 60-61.

Pérez-Reverte, A. (2002). La reina del sur. Barcelona, España: Alfaguara.

Promis, J. (2005). El neopolicial criollo de Ramón Díaz Eterovic. Anales de literatura chilena 6, 151-167.

Rascón Banda, H. (2008). Contrabando. Ciudad de México, México: Planeta.

Rincón, O. (2013). Todos llevamos un narco adentro. Un ensayo sobre la narco/cultura/telenovela como modo de entrada a la modernidad. MATRIZes 7(2), 1-33.

Sánchez Ríos, E. (2017). El cártel de los sapos I y Alias el mexicano: ¿empoderamiento de los personajes femeninos? Ánfora 24(43), 69-86.

Santos, D.; Vásquez Mejías, A. y Urgelles, I. (2016). Introducción. Lo narco como modelo cultural. Una apropiación transcontinental. Mitologías Hoy $14,9-23$.

Todorov, T. (1988). El origen de los géneros. Teoría de los géneros literarios (pp. 31-48). Madrid, España: Arco Libros.

Vallejo, F. (1994). La virgen de los sicarios. Medellín, Colombia: Alfaguara.

Vásquez Mejías, A. (2017). Apropiación cultural de lo narco en Chile: la narcoseries Prófugos. Revista Comunicación 26(2), 4-15.

Yépez, H. (2014). Nomos del norte: Nuevas tendencias de la recepción de la narcoliteratura mexicana entre medios, academia y gobierno. Miradas convergentes. Ensayos sobre la narrativa México-Estados Unidos (pp. 253-286). Ciudad de México, México: Artificios.

Zabalgoitia, M. (2010). Comparatismo latinoamericano y literatura popular y de masas: del estereotipo a nuevas construcciones de identidad en el encuentro de unos con otros. Castilla. Estudios de literatura 1, 420-432. 